\title{
O PATRIOTISMO CONSTITUCIONAL E A SOCIEDADE BRASILEIRA: UMA VISÃO CONTEMPORÂNEA
}

THE CONSTITUTIONAL PATRIOTISM AND THE BRAZILIAN SOCIETY: A CONTEMPORARY VISION

\section{Dorival Fagundes COtRIM JÚNIOR*}

\section{RESUMO}

O roteiro deste breve artigo é primeiro lançar algumas luzes sobre o conceito de Patriotismo Constitucional, que se tornou conhecido após o seu uso por Jürgen Habermas, apresentando um breve aspecto histórico do mesmo, a partir da sua formação. Posteriormente apresentam-se duas posições revisitadas do Patriotismo, de Arroyo e de Maia, que trazem interessantes discussões ao debate em outros países que não a Alemanha, sob um enfoque mais republicanista (Republicanismo) do que o próprio Habermas. Em seguida delineiam-se breves considerações sobre a sociedade brasileira atual, tendo como ponto de partida o advento da Carta Constitucional de 1988 (basilar para a nossa análise acerca do Patriotismo Constitucional no Brasil) e suas repercussões, verificando, por fim, se é possível aplicá-lo nas terras latino-americanas ou se essa tentativa não passa de uma apropriação acrítica de teorias europeias, cujo contexto políticoconstitucional difere em muitos aspectos do brasileiro.

Palavras-chave: patriotismo constitucional; Arroyo; Maia; republicanismo; apropriação acrítica.

\section{ABSTRACT}

The script of this brief article is first to shed some light on the concept of Constitutional Patriotism, which became known after its use by Jürgen Habermas, presenting a brief historical aspect of it, from its formation. Later, two revisited positions of Patriotism, Arroyo and Maia are presented, which bring interesting discussions to debate in countries other than Germany, under a more republicanist (Republicanism) approach than Habermas himself. Brief considerations on current Brazilian society are outlined below, starting with the advent of the 1988 Constitutional Charter (basilar for our analysis of Brazilian Constitutional Patriotism) and its repercussions, and verifying, finally, if it is possible to apply it in Latin American lands or if this attempt is an uncritical appropriation of European theories, whose political-constitutional context differs in many respects from Brazilian.

Keywords: constitutional patriotism; Arroyo; Maia; republicanism; uncritical appropriation.

* Mestrando em Direito Constitucional e Teoria do Estado pela Pontifícia Universidade Católica do Rio de Janeiro (PUC/RJ). Graduado em Direito pela Universidade Federal do Rio de Janeiro (UFRJ).

Bolsista da Coordenação de Aperfeiçoamento de Pessoal de Nível Superior (CAPES).

juninhogby@gmail.com 


\section{SUMÁRIO}

NOTA INTRODUTÓRIA; 1 O PATRIOTISMO CONSTITUCIONAL; 2 A POSIÇÃO REVISITADA DE ARROYO; 2.1 Retomando o Conceito; 2.2 Arroyo e o Vínculo com o Republicanismo; 3 PATRIOTISMO CONSTITUCIONAL NO BRASIL; 3.1 As contribuições de Maia; 3.2 Balanços Parciais; 4 É REALMENTE POSSÍVEL APLICAR ESTE CONCEITO NO BRASIL?; 4.1 A Democracia como um decisivo valor constitucional; CONCLUSÃO: DE QUEM DEPENDE O PATRIOTISMO CONSTITUCIONAL?; REFERÊNCIAS

\section{- NOTA INTRODUTÓRIA}

A título de introdução do artigo, elaborado com base em uma metodologia qualitativa e com pesquisa teórica, algumas considerações são importantes para esclarecer os leitores acerca do tema analisado, qual seja, o conceito de Patriotismo Constitucional e sua possível aplicação na sociedade brasileira, sendo este o problema que se investiga no curso do trabalho, cujo objetivo é justamente verificar se é razoável a importação do conceito.

O conceito de Patriotismo Constitucional foi popularizado por Jürgen Habermas e nos pareceu interessante diante do cenário brasileiro, uma vez que propõe a criação e o fomento da cultura política entre os cidadãos por meio de uma afinidade proveniente, por sua vez, da Carta Constitucional e que parece faltar no país ou é incipiente.

Além da posição do próprio Habermas, Velasco Arroyo e Antônio Maia são mais duas vozes trazidas para a discussão, o primeiro mais republicanista e o segundo ainda mais distante, que também objetiva uma análise deste conceito para uma possível aplicação no Brasil, sob dois parâmetros importantes: considerar que o país possui dimensão continental, com diferenças múltiplas entre as suas regiões e por isso imprescindível criar valores compartilhados; e que o país deseja possuir voz ativa forte no plano internacional, através do atendimento às reivindicações culturais das minorias - e conjugados formariam o nacionalismo reflexivo.

Por fim, demonstra-se a necessidade de considerar as peculiaridades da narrativa brasileira, como uma Constituição anacrônica em algumas circunstâncias; o não cumprimento das suas diretrizes pelos próprios agentes públicos, incluindo os do Judiciário; e o fato de que quando as pessoas vão às ruas protestar são agredidas injustamente pelos agentes estatais. Agenciando estas questões é que surge o questionamento final, qual seja, se este modelo de Patriotismo necessita ou exige a participação das instituições e dos seus agentes, no que se respondeu positivamente, haja vista que todos constituem tecido político e social do país e que a própria noção de Estado e dos seus papeis contribuem para a formação de um sentimento patriótico. Nesse sentido, a vinculação aos Direitos Humanos estabelecidos na Carta Constitucional é tarefa de todos; e assim, este conceito de Patriotismo precisa ser adaptado à realidade brasileira, diversa da alemã. 


\section{O PATRIOTISMO CONSTITUCIONAL}

Antes mesmo de delimitar o Patriotismo Constitucional é preciso tecer algumas diretivas acerca da pluralidade cultural, que é um dos temas mais debatidos no âmbito da filosofia política atualmente. Habermas afirma que em sociedades pós-convencionais da contemporaneidade há uma multiplicidade de formas de vida, que cresce continuamente, e também grandes divergências acerca da temática da diversidade cultural, que exigem o reconhecimento e as garantias de status de igualdade diante de outras concepções de vida.

Nessa toada que Habermas busca uma tentativa de reconstruir, reformular, reestruturar o Direito e a sua estrutura normativa, a fim de que elas sejam capazes de atender a uma variada e complexa gama de reivindicações de inclusão e de convivência pacífica em sociedades plurais destes tempos hodiernos.

Para tentar tal desiderato Habermas traz a noção do Patriotismo Constitucional, reinterpretado por vários outros pensadores, dentro e fora da Europa. O debate é levado até o nível constitucional, no qual se procura criar e posteriormente fomentar uma cultura política dos cidadãos que consiga fortalecer as amarrações e conexões identitárias da sociedade, simultaneamente procurando estar atento à diversidade, adotando-se uma visão mais republicana, mas sem esquecer completamente a via estabelecida pelo liberalismo ${ }^{1}$.

O tópico do Patriotismo Constitucional apareceu, primeiramente, no contexto da Alemanha Ocidental com o Historikerstreit ${ }^{2}$, consistindo nessa divergência de interpretação sobre o Nazismo por vários intelectuais alemães. Foi Habermas quem publicizou o teor político desta controvérsia, denunciando veemente o neo-historicismo e sua tentativa de reestruturar, ressignificando, após os eventos nefastos de Auschwitz, uma continuidade da identidade alemã.

A contribuição de Habermas no debate foi importante porque ele assumiu uma postura crítica e não pueril dessa perspectiva de tentar apresentar interpretações revisionistas dos tempos nazistas, principalmente capitaneada por historiadores conservadores, como Ernst Nolte ${ }^{3}$, tentando trivializar o significado de terror do Holocausto, que até hoje assombra a Europa, sobretudo a própria Alemanha, que tentam se recuperar desta ferida histórica.

Nesse sentido o patriotismo constitucional alemão significou o orgulho pela superação do Nazismo, estabelecendo uma ordem político-constitucional lastreada no Estado de Direito (ou Estado Democrático de Direito), e este, a seu turno, ancorado em uma cultura política de cunho liberal ${ }^{4}$. Então Habermas desenvolveu este conceito de Patriotismo

\footnotetext{
${ }^{1}$ Nesse sentido ver MONICA, Eder Fernandes. In: “A Ideia de Patriotismo Constitucional e Sua Aplicação no Brasil, 2007".

${ }^{2}$ Foi um debate entre os historiadores alemães a partir dos anos 1980, iniciado com a interpretação de Nolte do Nazismo, apresentando a tese de que o Nazismo e o mesmo o Holocausto teriam sido cópias do Bolchevismo. 0 historiador basicamente defendeu que o "nexo causal" entre ambas as experiências seria uma similitude de "extermínio de classes" por parte dos bolcheviques e "extermínio de raças" pelos nazistas. Disponível em: <http://blogjunho.com.br/ernst-nolte-e-a-historiografia-revisionista/>. Acessado em 07 de julho de 2017.

${ }^{3}$ Ver nesse sentido BUNCHAFT, Maria Eugênia. A Integração do Conceito de Patriotismo Constitucional na Cultura Política Brasileira, 2005. Publicado em Revista Direito, Estado e Sociedade da PUC-Rio.

${ }^{4}$ HABERMAS, Jürgen. Identidades Nacionales y Postnacionales. Madrid: Tecnos, 1998, p. 115-116.
} 
Constitucional como uma nova forma de prover um arquétipo (modelo) de identificação política capaz de sobrepujar, suplantar o nacionalismo alemão, conceituando a identidade nacional deste povo de uma forma diferente daquela que queriam estabelecer, qual seja, a neo-historicista alemã, não caindo nas garras de uma compreensão conservadora e minimalizante dessa história.

Esta noção de Patriotismo foi reinterpretado em moldes altamente republicanos por Juan Carlos Velasco Arroyo ${ }^{5}$, isto é, além do entendimento de Habermas e do qual se valerá Antônio Maia ${ }^{6}$, buscando a viabilidade deste conceito na cultura políticojurídica nacional, distanciando também da formulação original, uma vez que vê a miscigenação nacional racial e a etnicidade híbrida da população como ofertando um novo entendimento acerca do Patriotismo, que poderia fortalecer a identidade nacional brasileira.

Apresentaremos um pouco destas posições de Juan Arroyo e Antônio Maia, elaborando, pari passu, algumas críticas, tanto durante a própria exposição quanto em um tópico separado.

\section{A POSIÇÃO REVISITADA DE ARROYO}

Segundo se defende na Ciência Política e também nas Jurídicas, os Estados modernos com suas cartas constitucionais se mostram como estruturas político-jurídicas destinadas a assegurar uma convivência razoável em sociedades territorialmente delimitadas, nas quais a unidade religiosa e/ou cultural tinha-se despedaçado, em virtudes de discrepâncias que se defendiam inconciliáveis entre si.

Uma solução para tal questão foi o desenho de acordos neutros de natureza procedimental a fim de regular estas complicadas matérias. Acontece que atualmente novas tensões aparecem (ou ressurgem), em virtude das demandas de reconhecimento de formas coletivas de identidade, o que nos leva invariavelmente ao questionamento quanto a possibilidade de uma constituição moderna poder reconhecer simultaneamente diversas manifestações de culturas e adequadamente tratá-las, isto é, equanimemente e não com preferências, seja de aspecto positivo, seja de aspecto negativo ${ }^{7}$.

Para Habermas, atualmente os tecidos sociais estão experimentando uma grande variedade de manifestações culturais de vida, de grupos étnicos-raciais ${ }^{8}$, de religiões e formas

\footnotetext{
${ }^{5}$ ARROYO, Juan Carlos Velasco. 2004. “Republicanismo, constitucionalismo y diversidad cultural. Más allá de la tolerancia liberal”. In: Revista de Estudios Políticos, no 125, pp. 181-209.

${ }^{6}$ MAIA, Antonio C. S. C. 2005. "Diversidade cultural, identidade nacional brasileira e patriotismo constitucional". In: Diversidade Cultural Brasileira: Edições Casa de Rui Barbosa. Rio de Janeiro, p. 115-156. Disponível em: <http://www.casaruibarbosa. gov.br/seminario/DiversidadeCultural/Antonio_Cavalcanti.pdf>. Acessado em 07 de Julho de 2017.

7 ARROYO, Juan Carlos Velasco. "Republicanismo, constitucionalismo y diversidad cultural. Más allá de la tolerancia liberal". In: Revista de Estudios Políticos, no 125, 2004, p. 181.

8 Para uma abordagem educacional dessa diversidade cultural e étnico-racial, apresentando os desafios para a educação diante deste tema, ver SILVA, Giovani José da; SOUZA, José Luiz de. Educar Para a Diversidade ÉtnicoRacial e Cultural: Desafios da Educação Inclusiva no Brasil. Disponível em: < https://www.revistas.ufg.br/interacao/article/view/4256/4180>. O artigo só representa a atualidade da
} 
de compreensão do mundo, de forma que se faz impossível a defesa de modelos antigos, já defasados, para lidar com o problema da diversidade, que tem um significado muito denso para os povos atuais, sendo de fundamental importância, sobretudo quando se fala dos problemas das minorias. Nesse sentido a importância do tema se afirma, sendo preciso ainda uma visão mais republicanistas da questão ${ }^{9}$.

Arroyo vai buscar a viabilidade da aplicação do Patriotismo Constitucional em sociedade hiper-plurais, orientando o seu foco para uma tentativa de resolver constitucionalmente este imbróglio.

De plano ele faz a distinção entre os três modelos básicos de comunidade política, que tentam lidar politicamente com o pluralismo identitário. O primeiro molde (i) é o universalista (do liberalismo), segundo o qual as instituições políticas públicas aparecem com o escopo de garantir a identidade individual, sendo certo afirmar que este é o modelo que prima pela Autonomia Pessoal. O segundo modelo (ii) é o Comunitarista, mais particularista, cujas versões contemporâneas têm apresentado alguns traços do próprio nacionalismo, concebendo a comunidade pública como servindo fundamentalmente para a manutenção da identidade de comunidades. O terceiro modelo (iii) é o republicano, que arquiteta a comunidade política como sendo ela própria uma expressão de uma identidade "cívica", exigindo de seus membros um compromisso ativo com os assuntos públicos ${ }^{10}$.

Pontua Arroyo que certa forma de republicanismo se apresenta como a maneira plausível de superar o dualismo entre liberalismo e nacionalismo, sendo que o seu objeto, ao menos pelo que depreendemos das leituras, seria considerar a possibilidade de uma política identitária capaz de abarcar as diferenças no campo da cultura; e que se faça situada normativamente para além da tolerância passiva do liberalismo procedimental ${ }^{11}$, utilizando para tal o desenho dos republicanistas ${ }^{12}$.

O Liberalismo não responderia a altura porque essas manifestações plurais culturais reivindicam não somente o reconhecimento ${ }^{13}$ das suas diferenças (de tipo simbólico ou não), mas também um reconhecimento das suas próprias formas de desenhos comunitários e

temática, inclusive de caráter interdisciplinar, demonstrando que é uma matéria de interesse de outras áreas também, que não somente à jurídica e à política.

${ }^{9}$ HABERMAS, Jürgen. A Inclusão do Outro. Tradução George Sperber. São Pau-lo: Loyola, 2002, p. 134.

10 ARROYO, Juan Carlos Velasco. "Republicanismo, constitucionalismo y diversidad cultural. Más allá de la tolerancia liberal". In: Revista de Estudios Políticos, no 125, 2004, p. 182-3. Para mais noções acerca do Republicanismo e também do Comunitarismo consultar a obra didática de GARGARELLA, Roberto. As Teorias da Justiça Depois de Rawls - Um Breve Manual de Filosofia Política. 1a edição. São Paulo: Editora Martins Fontes, 2008, p. 183 e seguintes; e p. 137 e seguintes, respectivamente.

11 Do qual Habermas se faz expoente.

12 ARROYO, Juan Carlos Velasco. "Republicanismo, constitucionalismo y diversidad cultural. Más allá de la tolerancia liberal”. In: Revista de Estudios Políticos, no 125, 2004, p. 183-4. Salienta-se que o autor está se ocupando de responder às particularidades do caso da Espanha, que convive com diversidade cultural.

13 Quem procurar uma doutrina específica sobre o reconhecimento enquanto categoria importante para a construção de uma teoria e prática da justiça, consultar a obra de HONNETH, Axel. Luta por Reconhecimento: A Gramática Moral dos Conflitos Sociais. Tradução de Luiz Repa; apresentação de Marcos Nobre. São Paulo: Editora 34, 2003, p. 155 e seguintes. 
jurídicos. Somente a promoção do igualitarismo não garante a sobrevivência das formas de vida e de culturas, sendo preciso que o Estado preserve os traços distintivos da comunidade ${ }^{14}$.

Arroyo aponta que os sistemas democrático-liberais, quando desenvolveram o instituto da tolerância tinham o problema da convivência das religiões para resolver, separando e criando duas esferas para cada, uma para a religião e outra para o Estado. Todavia, hodiernamente o problema da tolerância não é só mais religioso, mas também questões de nacionalismos, imigrações, minorias étnico-raciais, etc., necessitando-se de novas bases $^{15}$.

Tolerância para o autor estaria no sentido de uma "atitude de diálogo com os adversários e a capacidade de revisar as próprias ideias, uma 'disposição à cooperação e à busca de conciliações ${ }^{16 "}$. Parece-nos que o autor diferencia tolerância da ideia de reconhecimento do outro e o direito deste de alteridade, sendo que reconhecer implica muito mais do que simplesmente tolerar ${ }^{171819}$.

Para o Republicanismo não há a necessidade de homogeneidade étnico-cultural, seja para o estabelecimento, seja para a consolidação de uma comunidade política, sendo o modelo caracterizado por três noções básicas: (i) a de participação do cidadão; (ii) de primazia do "povo" e (iii) de deliberação pública²0.

Eles preconizam uma forte noção de cidadão, como é bem conhecido, mas segundo alguns, como Arroyo, não se é possível fazer uma das críticas mais conhecidas a eles ${ }^{21}$, qual

\footnotetext{
${ }^{14}$ Exemplo são as leis especiais válidas para a província de Quebec, no Canadá, que se orienta com base neste protecionismo estatal.

15 ARROYO, Juan Carlos Velasco. "Republicanismo, constitucionalismo y diversidad cultural. Más allá de la tolerancia liberal". In: Revista de Estudios Políticos, no 125, 2004, p. 192

${ }^{16}$ ARROYO, Juan Carlos Velasco. "Republicanismo, constitucionalismo y diversidad cultural. Más allá de la tolerancia liberal”. In: Revista de Estudios Políticos, no 125, 2004, p. 193.

${ }^{17}$ ARROYO, Juan Carlos Velasco. "Republicanismo, constitucionalismo y diversidad cultural. Más allá de la tolerancia liberal”. In: Revista de Estudios Políticos, no 125, 2004, p. 195.

${ }^{18}$ Sobre uma perspectiva da tolerância, ver o interessante estudo de WALZER, Michael. Da tolerância. São Paulo: Martins Fontes, 1999. Nas páginas 16 a 18, por exemplo, ele afirmará que pessoas tolerantes "são aquelas que aceitam homens e mulheres cujas crenças não adotam, cujas práticas se recusam a imitar". Parece que Walzer põe a tolerância como uma virtude que pode se expressar de várias formas e elenca algumas possibilidades contextuais nas quais a tolerância pode vir a ocorrer, sendo: (1) aceitação da diferença para a continuidade da paz; (2) atitude de indiferença diante de certa diferença; (3) reconhecimento do direito do outro sujeito mesmo quando o exercício deste seja "antipático"; (4) em atitude de respeito e de certa disposição ao outro, no sentido de ouvi-lo e buscar um aprendizado; e (5) o endosso entusiástico da diferença, seja ela estética ou funcional. Portanto, é perceptível que tolerância não se limita à aceitação daquele que pensa e toma atitudes diferentes do outro, mas se refere, em geral, se nos é lícito resumir, a uma defesa ou respeito à liberdade individual do outro. Quem desejar saber mais sobre, favor consultar também FAVARIM, Flávia Negri. Limites da Tolerância Nos Conflitos Entre Grupos Religiosos. 2007. 113 f. Dissertação (Mestrado em Direito) - Programa de Pós Graduação em Direito, Universidade Metodista de Piracicaba, São Paulo. 2007, p. 22 e seguintes.

${ }^{19}$ Há ainda quem defenda a tolerância às diversidades como sendo a base da efetivação de uma sociedade democrática, justa e igualitária. Somente a partir da tolerância é que haverá a possibilidade de uma convivência harmoniosa e a concretização de uma sociedade livre de discriminações e violências desse teor. Nesse sentido consultar o interessante trabalho de LEISTER, Margareth A.; TREVISAN, Elisaide. A Tolerância às Diversidades: Base da Efetivação da Sociedade Democrática. In: Ana Maria Viola de Sousa; Noe Lopes Zuñiga; Grasielle Augusta Ferreira Nascimento. (Org.). Direitos Humanos e Minorias. 1edição. Lorena: UNISAL, 2015, v. 4, p. 1-12.

20 ARROYO, Juan Carlos Velasco. "Republicanismo, constitucionalismo y diversidad cultural. Más allá de la tolerancia liberal”. In: Revista de Estudios Políticos, no 125, 2004, p. 196.

${ }^{21}$ Feita inclusive por Habermas ao longo das suas obras.
} 
seja, de que tudo se deixa à boa disposição dos cidadãos (a supremacia da Soberania Popular), pois haveria alguns imperativos funcionais que necessitam de regras claras. Isso porque se todos os cidadãos fossem virtuosos todo o tempo não haveria necessidade de desenhos político-institucionais contra a corrupção ou de balanceamento dos poderes.

Ele aponta ${ }^{22}$ que isto bastaria para se ter uma concepção republicana sem abandonar completamente alguns apelos do liberalismo, além de argumentar no sentido de que outras críticas que foram feitas ao republicanismo foi porque aqueles associaram irrefletidamente o patriotismo republicano com o nacionalismo (visto como promotor de políticas excludentes e negativas).

Nesse sentido, o patriotismo, mesmo derivado de uma práxis republicana, é primariamente de ordem cívica e não repousa sobre componentes étnico-culturais, como foram os laços de sangue, a língua e a religião. Do cidadão deve-se esperar somente a lealdade aos princípios democráticos sobre os quais o Estado se configura e não com a identificação com algum conteúdo substancial etno-cultural ou mesmo com alguma concepção de bem.

Isto decorreria do fato de que o Estado só pode comprometer-se com uma diversidade cultural, declarando interesse cultural somente de forma ampla, mostrando, portanto, sensibilidade política pelo caleidoscópio cultural - logo, assumindo uma gestão democrática da diferença. Assim, e somente assim, é que se poderá exigir lealdade dos cidadãos perante o Estado, pois este não entraria em conflito com as identidades particulares de cada um ${ }^{23}$.

É razoável também mostrar a relação de complementariedade que existe entre identidade coletiva e identidade cultural. Ora, discutindo-se questões de identidades coletivas, em dimensões nacionais, é preciso considerar que há várias identidades culturais dentro daquele espaço político, que envolve uma identidade nacional. No mundo moderno, como foi destacado, é comum o fato de uma pessoa pertencer a diversos grupos de identificação ${ }^{24}$.

Assim, é difícil delimitar o sujeito, cerceá-lo em certa identidade coletiva, tentando adivinhar quais seriam as suas interações com outros sujeitos. O indivíduo só se reconhece quando está vinculado a uma cultura específica e seus desdobramentos, como a língua, formando a sua identidade pessoal. Nas sociedades contemporâneas (sociedade de estranhos, segundo Habermas ${ }^{25}$ ) o sujeito tem o direito de escolher participar de vários códigos culturais ou mesmo de nenhum.

Já entre a construção social das identidades coletivas é preciso diferenciar, vez que há entre essas identidades (coletiva e pessoal) somente uma relação de complementariedade e não de analogia. Por conseguinte, as identidades coletivas têm de serem conceituadas de forma genérica, pois forjadas em comum sobre uma base cultural que necessariamente pressupõe a emergência de instâncias responsáveis por suas definições e administração. A

\footnotetext{
${ }^{22}$ ARROYO, Juan Carlos Velasco. "Republicanismo, constitucionalismo y diversidad cultural. Más allá de la tolerancia liberal”. In: Revista de Estudios Políticos, no 125, 2004, p. 198-9.

${ }^{23}$ ARROYO, Juan Carlos Velasco. "Republicanismo, constitucionalismo y diversidad cultural. Más allá de la tolerancia liberal". In: Revista de Estudios Políticos, no 125, 2004, p. 200.

${ }^{24}$ Um grupo da igreja, de amigos, dos jogos, de trabalhos, etc.

${ }^{25}$ HABERMAS, Jürgen. O Estado-nação europeu frente aos desafios da globalização. In: Novos Estudos CEBRAP, n. 43, novembro de 1995, p. 97
} 
nação, para Habermas, é uma forma moderna de identidade coletiva, sendo comunidades socialmente erigidas e que se nutrem de tradições inventadas ${ }^{26}$.

Pelo exposto, há a necessidade de reformulação do conceito de patriotismo, tendo em vista que a tarefa do Estado de gerir um consenso democrático e de formar uma identidade coletiva atenta às singularidades se vê facilitada, caso a vida em comum se assente neste consenso constitucional ${ }^{27}$. Esse patriotismo engloba um esforço de construir uma noção de força motivadora, funcionando como vetor de união de populações plurais e estranhas entre si, desvinculadas do partilhamento de religiões, nações, idiomas, territórios ou história em comum. Há claramente uma recusa aos pertencimentos pré-políticos, incapazes de garantir a solidariedade entre estranhos ${ }^{28}$.

\subsection{Retomando o Conceito}

É preciso retomar brevemente, novamente, o que se pode entender por Patriotismo Constitucional, apontando uma nota histórico-conceitual não citada na primeira parte deste artigo, que diz respeito ao alemão Dolf Sternberger, o criador do termo, que à época buscava novos princípios e diretrizes constitucionais sobre os quais deveria ser fundamentada a vida política alemã depois da II Guerra Mundial. Aos fins dos anos 70 ele afirmou que a Carta Constitucional Alemã conseguiu reformar os sentimentos dos cidadãos, no momento em que estes começaram a admirar, respeitar e apreciar esta Carta, contribuindo para o surgimento de um novo patriotismo, não sustentado nos tradicionais elementos do pertencimento (língua, história, etnia), mas politicamente lastreado na Lei Fundamental ${ }^{29}$.

Nesse sentido o termo foi usado, sinteticamente, para se referir a esse processo coletivo de identificação dos cidadãos alemães no pós-Guerra. É certo que diante dos fatos catastróficos realizados, não haveria como ter orgulho do passado, representando este conceito uma nova construção de uma nação alemã, pautada na prática e no direito de participação dos cidadãos.

Nos anos 90 é que Habermas reformula os termos, ao analisar duas questões principais: (i) as discussões do multiculturalismo, que o levaram a reconhecer a legitimidade das diferentes formas e concepções de vida; e (ii) as questões sobre a União Europeia, estendendo o conceito para toda a Europa ${ }^{30}$.

\footnotetext{
${ }^{26}$ ARROYO, Juan Carlos Velasco. "Republicanismo, constitucionalismo y diversidad cultural. Más allá de la tolerancia liberal". In: Revista de Estudios Políticos, no 125, 2004, p. 197.

27 ARROYO, Juan Carlos Velasco. "Republicanismo, constitucionalismo y diversidad cultural. Más allá de la tolerancia liberal”. In: Revista de Estudios Políticos, no 125, 2004, p. 201.

${ }^{28}$ MAIA, Antônio C. "Diversidade cultural, identidade nacional brasileira e patriotismo constitucional". In: Diversidade Cultural Brasileira: Edições Casa de Rui Barbosa. 2005, Rio de Janeiro, p. 13-4.

29 MAIA, Antônio C. "Diversidade cultural, identidade nacional brasileira e patriotismo constitucional". In: Diversidade Cultural Brasileira: Edições Casa de Rui Barbosa. 2005, Rio de Janeiro, p. 12.

30 MAIA, Antônio C.. "Diversidade cultural, identidade nacional brasileira e patriotismo constitucional". In: Diversidade Cultural Brasileira: Edições Casa de Rui Barbosa. 2005, Rio de Janeiro, p. 15.
} 


\subsection{Arroyo e o Vínculo com o Republicanismo}

Arroyo aponta que, para ele, o Patriotismo Constitucional está fortemente vinculado ao Republicanismo, sendo necessário, portanto, conhecer e assumir os valores básicos desta tradição política ${ }^{31}$. Dessa forma o patriotismo está ancorado em uma identificação reflexiva, não com conteúdos particulares de uma tradição específica de cultura, mas com conteúdos universais recolhidos da ordem normativa e ratificada ou posta primeiramente na própria Constituição, quais sejam: os Direitos Humanos e os Direitos Fundamentais do Estado de Direito 32 .

Torna-se nítido que essa concepção evita as tradições ufânicas de passados gloriosos, tão usuais nos discursos nacionalistas, bem como as apropriações destes. Ratificando essa posição, definido pelo pluralismo cultural, razoável utilizar uma fórmula descrita por Habermas: "articular a unidade da cultura política na multiplicidade de subculturas e formas de vida ${ }^{33 "}$. Por isso a cultura democrática nesse país deve afastar qualquer tentativa particularista de exclusão de qualquer forma de vida que seja.

Mas como realizar esta integração de pluralidades de visões de mundo, considerando que há uma unidade para uma multiplicidade? Segundo Habermas, em que pese a falta de consenso substancial sobre os valores, os cidadãos dessas sociedades pós convencionais apelam a convicções e normas morais que devem ser partilhadas por todos. Nesse sentido a integração social necessita de um agir orientado por um acordo mútuo de todos, lastreado sobre o reconhecimento de reivindicações ${ }^{34}$.

Nas sociedades pós-convencionais, como se sabe, Habermas tenta explicar a integração social (pois não há mais um ethos tradicional) por meio do modelo dos discursos racionais, que podem ser vistos como formas especializadas da ação comunicativa, no sentido de que as argumentações racionais são as únicas permitidas neste sistema. Os discursos são procedimentos que reproduzem a busca coletiva e conjunta da verdade, da retidão e da sinceridade e nesse meio tempo pluraliza-se as visões de mundo e as concepções de vida boa $^{35}$.

Nesse aspecto o Direito precisa assegurar a procura cooperativa das pretensões de validade nessas sociedades pós-convencionais, não sendo apenas o local de conflito de interesses, mas de busca do entendimento, abrindo um espaço para comunicação entre todos esses indivíduos fragmentados. Nessa toada é ingênuo dizer que Habermas não reconhece o

\footnotetext{
${ }^{31}$ ARROYO, Juan Carlos Velasco. "Republicanismo, constitucionalismo y diversidad cultural. Más allá de la tolerancia liberal”. In: Revista de Estudios Políticos, n 125, 2004, p. 33-4.

32 ARROYO, Juan Carlos Velasco. "Republicanismo, constitucionalismo y diversidad cultural. Más allá de la tolerancia liberal". In: Revista de Estudios Políticos, no 125, 2004, p. 34.

33 ARROYO, Juan Carlos Velasco. "Republicanismo, constitucionalismo y diversidad cultural. Más allá de la tolerancia liberal”. In: Revista de Estudios Políticos, no 125, 2004, p. 35.

${ }^{34}$ HABERMAS, Jürgen. A Inclusão do Outro. Tradução George Sperber. São Pau-lo: Loyola, 2002, p. 93-4.

35 MONICA, Eder Fernandes. "A Ideia de Patriotismo Constitucional e Sua Aplicação no Brasil". Confluências: Revista Interdisciplinar de Sociologia e Direito, 2007, p. 8.
} 
conflito ou a sua existência, mas apenas busca delimitar formas de superá-lo, por meio do entendimento ${ }^{36}$.

Com o Direito fica garantido o desenvolvimento das culturas e práticas comunitárias, firmando elementos de coesão e solidariedade, não desconsiderando mecanismos de coordenação e algum sentido do comum, no qual todos venham a se reconhecerem. Surgem então duas vias de integração: (i) uma étnico-cultural, que aglutina-se em torno das diversas formas de vida particulares, tradições, etc.; e (ii) outra que é político-cultural, mais abstrata, cujo núcleo são os princípios que possibilitam a vida em comum. O Estado, como é óbvio, deve se pautar neste segundo tipo, exigindo dos cidadãos somente a cultura política dentro de um espaço cívico que preserve a identidade coletiva ${ }^{37}$.

Uma diferenciação se faz interessante para esclarecimento do assunto, no que diz respeito ao Ethnos e Demos, sendo este uma nação de cidadãos (visão cívica) e aquele uma nação, vista como comunidade de destino de um povo (perspectiva étnico-cultural) ${ }^{38}$.

Os conflitos surgem quando essas instâncias estão em conflito e um adquire prevalência substancial sobre o outro. Um excesso no primeiro, consciência nacional, desenrola em fundamentalismo complacente; e uma ênfase no ideal republicano pode fragmentar a sociedade. Então é a ideia de Patriotismo Constitucional que servirá a Habermas como um instrumento de equilíbrio estas ambas as concepções.

O sentimento de pertencimento criado, desenvolvido, fomentado e estruturado nesta comunidade terá como esteio os valores democráticos e o respeito aos direitos humanos protegidos constitucionalmente por determinado país, levando a construção de uma consciência nacional, sem particularismos, mas com respeito ao diferente. Essa cultura política comum que Habermas tenta estabelecer deve ser uma condição de possibilidade às múltiplas reivindicações culturais e formas de vida.

Há alguns problemas nestas sociedades pós-convencionais que se referem à humanidade em geral e não somente a projetos específicos de vida, seja individual ou coletivo. Assim, diferenciando-se dos discursos éticos, a ideia de Patriotismo no Brasil adotará o ponto

\footnotetext{
36 MIGUEL, Luis Felipe. Consenso e conflito na teoria democrática: para além do "agonismo". Lua Nova (Impresso), v. 92, p. 13-43, 2014, apresenta e defende esta visão, de uma forma muito técnica, com nítido esmero, apresentando a ênfase que foi dada nas últimas décadas aos processos de produção do consenso, deslocando a centralidade do conflito político, como é o caso de Habermas e também de Rawls. Em seguida, neste estudo, ele apresenta a denúncia de Chantal Mouffe a este movimento, afirmando a irredutibilidade do conflito político. Por fim, ele diferencia a categoria "povo" como não sendo uma categoria econômica ou de classe, mas política, que "reúne" as pessoas que estão submetidas a um governo (p. 39). Nesse sentido, povo se contrapõe a governo e com isso em mente, democracia não pode ser uma forma acabada de governo, mas "um projeto de enfrentamento das estruturas de dominação vigentes em determinada sociedade". Portanto, governos democráticos só podem ser vistos como respostas parciais, desafiada continuadamente por novas exigências, novas pautas políticas, de um lado; e de outro, sempre ameaçadas pelos nefastos "movimentos de oligarquização e acomodação", em um processo sempre inacabado. A partir disso pode-se verificar que liberdade e igualdade são valores em disputa constante e o recurso a eles apenas ressitua o antagonismo existente - para os dominados a democracia é a busca pela superação da dominação, que se mostra concretamente; e "o antagonismo entre dominantes e dominados pode se expressar ou mesmo ser escamoteado, mas não há fórmula retórica que o faça ser transcendido (p. 40). Daí a crítica dele a Chantal Mouffe também.

37 ARROYO, Juan Carlos Velasco. "Republicanismo, constitucionalismo y diversidad cultural. Más allá de la tolerancia liberal". In: Revista de Estudios Políticos, no 125, 2004, p. 201-2.

38 ARROYO, Juan Carlos Velasco. "Republicanismo, constitucionalismo y diversidad cultural. Más allá de la tolerancia liberal". In: Revista de Estudios Políticos, no 125, 2004, p. 199.
} 
de vista moral ${ }^{39}$, buscando uma autodeterminação de todo e qualquer ser humano, mas sendo legítimas somente as normas que tenham o assentimento de todos.

Todavia, Habermas aponta ainda que os cidadãos devem ter a capacidade de seguilas de forma consciente, através do autoesclarecimento, julgando essas tradições, a fim de se evitar uma conservação forçada de espécies culturais e que não afronte as liberdades individuais. Portanto, o papel do Estado aqui parece ser a de não interferência para promoção efetiva e direta de certo tipo cultural.

Para os liberais, o que prevalece é a autonomia privada de cada sujeito e para os republicanos é a autonomia pública, ou o que se denomina de soberania popular, polarização bem conhecida de todos os ligados ao tema ${ }^{40}$. E a proposta de Habermas vem no sentido de superar essa divergência, de forma que o Estado só venha a exigir do cidadão um civismo consoante os princípios políticos do próprio estado de direito, lastreado na Carta Constitucional de cada país, mais sensível às diferenças (as mais variadas possíveis, como culturais, étnico-raciais, entre outros) e que permita a inclusão do outro, isto é, do diferente, do que não é ou representa o próprio ser.

Para que isto funcione Habermas utiliza-se de um modelo constitucional aberto, com acesso cidadão regulado por procedimentos claros, exigindo-se do cidadão a aceitação da Carta Constitucional nos moldes desenhados. Habermas desenvolve esta ideia compreendendo o dispositivo constitucional como um constructo dinâmico, em contínuo movimento e mutação, como um desenho inconcluso e sem fundo essencialista, substancialista, justamente porque não se vincula a nenhuma concepção de vida boa.

Para que o Estado não se destrua existe uma necessidade de compensação que só é suprida por uma democratização progressiva ${ }^{41}$, isto é, a constituição vista como um projeto na qual a sociedade civil pode influir sobre si mesma e no projeto por meio de processos discursivos. Para ele, este tipo de acordo constitucional é que torna possível a multiplicação de identidades diversas, compatíveis com apenas uma lealdade, qual seja, a constitucional (princípios universais fundamentais e direitos humanos).

Realizando uma leitura atenta do tema, percebe-se que o Estado Democrático não consegue ser neutro diante das concepções de bem, pois há nele, congenitamente, uma substância ética, qual seja, os direitos humanos e os princípios universais, baseados e respeitados a partir do Patriotismo Constitucional. Nesse sentido, esse modelo de política e de sociedade é somente mais um modelo, mas que o autor entende ser o razoável às sociedades modernas, mas não necessariamente boa para todos os povos.

Uma dificuldade que se apresenta para o Patriotismo é a sua baixa carga emocional (diante, por exemplo, da construção de nação, que apela fortemente ao coração, vez que

\footnotetext{
${ }^{39} \mathrm{O}$ ético diz respeito à concepção de bem que se deve seguir.

${ }^{40}$ SILVA, Ricardo. Visões da liberdade: republicanismo e liberalismo no debate teórico contemporâneo. Lua Nova: Revista de Cultura e Política, p. 181-215, 2015. Neste artigo instigante o autor apresenta a diferenciação de ambas as correntes em relação ao conceito de liberdade, apresentando-o como conceito "essencialmente contestado". Portanto, ajuda a esclarecer um pouco mais essa diferenciação entre as correntes, mesmo que no final o autor porá em xeque algumas das ideias dominantes, pontuando, com prudência, que ambas as visões de liberdades têm os seus próprios méritos e que não se apagam (uma a outra).

${ }^{41}$ MONICA, Eder Fernandes. "A Ideia de Patriotismo Constitucional e Sua Aplicação no Brasil”. Confluências: Revista Interdisciplinar de Sociologia e Direito, p. 5-22, 2007, p. 11.
} 
pautadas historicamente em uma constante construção), que procura ser compensado com um esforço maior na argumentação racional.

Mas se as razões, logo, os processos discursivos, precisam ser vinculadas às emoções, a fim de permitir uma mobilização dos diversos agentes sociais, o Patriotismo Constitucional tem por tarefa recuperar a linguagem das virtudes do civismo, essas, por sua vez, pautadas no amor às instituições políticas e ao modo de vida que dá conteúdo à liberdade dos cidadãos ${ }^{42}$.

Arroyo aponta que uma democracia participativa tem de estar unida ao sentimento de amor à pátria, revivendo o que sustentava A. Tocqueville: "o melhor modo de fazer os homens se interessarem por sua pátria é o fazê-los participar em seu governo ${ }^{43 \prime 44}$. A lealdade à Constituição será tanto mais forte à medida que os cidadãos mais se fizerem presentes no processo de formação e discussão público-políticos, suscitando uma responsabilidade partilhada com todos. A Constituição é essa carta que consagra um espaço de liberdade no qual os cidadãos tornam-se protagonistas da gestão e da fiscalização dos temas públicos, definindo também o que seja público e o que não se encaixa como tal, sendo claro que não há liberdade plena, completa, quanto ao texto constitucional (lembre-se que Habermas não advoga a supremacia da vontade do povo), mas conferindo esse aspecto contingente ao texto, sendo uma boa Constituição aquela que seja sensível à convivência humana, diferente por natureza.

Arroyo conclui suas ideias sobre a temática delimitando a sua concepção republicanista de política, como sendo um mínimo denominador comum, no qual se afinam ideologias e culturas diversas. Para o autor, no caso da Espanha, é convincente o patriotismo da pluralidade, pois por meio de um republicanismo da multiplicidade seriam movimentados sentimentos identitários no conjunto dos cidadãos, fazendo por emergir uma cultura pública plurinacional e pluriétnica ${ }^{45}$.

\section{PATRIOTISMO CONSTITUCIONAL NO BRASIL}

\subsection{As contribuições de Maia}

Aliado à proposta que estabelecemos para o artigo, qual seja, a de tentar aplicar o Patriotismo à realidade brasileira, invoca-se primeiramente Antônio Cavalcanti Maia, para só depois apresentarmos a nossa contribuição. Maia propõe que este conceito no país deveria assumir uma abordagem mais radical, já que a nossa Constituição Federal de 1988 é progressista, contendo em seu bojo variados direitos sociais, funcionando como pauta para

\footnotetext{
42 ARROYO, Juan Carlos Velasco. "Republicanismo, constitucionalismo y diversidad cultural. Más allá de la tolerancia liberal”. In: Revista de Estudios Políticos, no 125, 2004, p. 35.

43 MONICA, Eder Fernandes. "A Ideia de Patriotismo Constitucional e Sua Aplicação no Brasil". Confluências: Revista Interdisciplinar de Sociologia e Direito, p. 5-22, 2007, p. 13.

${ }^{44}$ TOCQUEVILLE, Alexis de. A Democracia na América. Trad. Neil Ribeiro da Silva. 1ạ ed. São Paulo: Folha de São Paulo, 2010, p. 179: "o meio mais eficaz e talvez o único que nos resta de interessar os homens pela sorte da sua pátria é fazê-los participar de seu governo". A citação do original nesta tradução é essa.

45 ARROYO, Juan Carlos Velasco. "Republicanismo, constitucionalismo y diversidad cultural. Más allá de la tolerancia liberal”. In: Revista de Estudios Políticos, № 125, 2004, p. 207.
} 
demandas políticas distributivas, fundamentais para a realidade brasileira, vergastada pela imensa e cruel desigualdade sócio-econômica entre as classes ${ }^{46}$.

Ainda é preciso salientar que a Carta de 88 é motivo de orgulho para os brasileiros, eis que representa um momento de transição entre governos autoritário-ditatoriais para o regime democrático e que a auto-estima é um elemento não presente na cultura nacional, podendo o Patriotismo ser um modo de superar esta falha ${ }^{47}$.

Ele as afasta de Habermas quando afirma que no Brasil deve-se buscar o Patriotismo com paixão e discursos retóricos, talvez por haver necessidade de um impulso maior, diante da precariedade do sistema nacional. $O$ autor é ainda muito otimista quando vê o Brasil como miscigenado racialmente, não sendo necessariamente vinculante o patriotismo com racismo/xenofobia, com base no nacionalismo integrativo ${ }^{48}$.

Maia afirma a necessidade de rearticulação da própria história nacional com base em uma reflexão de auto-consciência nacional coletiva, a partir de dois parâmetros: (i) um externo e (ii) outro interno. O externo, diante das dimensões continentais do país e das diferenças nas regiões, sobretudo as econômicas, não se pode abandonar a imprescindibilidade de criar valores compartilhados, que permita um engajamento cívico e a realocação de recursos para seguir o interesse republicano. No segundo se apresenta a vontade nacional de ser voz ativa forte no plano internacional, atendendo as reivindicações culturais minoritárias ${ }^{49}$.

Defende ainda a desvinculação do Patriotismo e Nacionalismo das características adquiridas durante a Ditadura Militar. Portanto, postula um nacionalismo reflexivo, nos moldes apresentados aqui.

Com base nisso, alia-se a um autor indiano Aijaz Ahmad, quando este advoga que nem o Brasil e nem a Índia são capazes de se ajustarem às teorias de nação e nacionalismo

\footnotetext{
${ }^{46} \mathrm{E}$ com perspectivas de piorar, diante das reformas trabalhistas que almejam retirar direitos mantidos durante os longos com muita resistência e luta, que aparecem na contramão das relativas conquistas que se vinham alcançando de uns para cá neste campo social, em algumas áreas, sobretudo a partir de 2003, quando Luís Inácio Lula da Silva assumiu a presidência do país. Vide, por exemplo, o combate a pobreza e a relativa melhora no campo da educação.

47 MAIA, Antônio C. "Diversidade cultural, identidade nacional brasileira e patriotismo constitucional". In: Diversidade Cultural Brasileira: Edições Casa de Rui Barbosa. 2005, Rio de Janeiro, p. 17.

${ }^{48}$ Para pensamentos contrários, ver, dentre muitos: Costa, Sérgio. Dois Atlânticos - Teoria Social, Anti-racismo e Cosmopolitismo. Disponível em: <https://books.google.com.br/books?hl=pt-BR\&lr=\&id=7p4w8tGqFcC\&oi=fnd\&pg=PA7\&dq=dois+atlanticos+sergio+costa+\&ots=wu1aJ0U_Sx\&sig=s6rk5SfBgXGQ7iulbg y3p0LCPMw>. Acessado em 01 de julho de 2017.

49 MAIA, Antônio C. "Diversidade cultural, identidade nacional brasileira e patriotismo constitucional". In: Diversidade Cultural Brasileira: Edições Casa de Rui Barbosa. 2005, Rio de Janeiro, p. 6 e 7.
} 
vindas da Europa ${ }^{50}$. E uma busca crescente de afastar os nacionalismos racistas do final do século XIX e primeira metade do $X X^{51}$.

Portanto, diante da também experiência negativa com a constatação de fatos históricos, os brasileiros não devem se fixar em originalidades construídas historicamente, mas sim que se busque o futuro, permeado da noção de constituição como um projeto de sociedade e não somente de juristas, cientistas, filósofos, letrados em geral.

O nacionalismo brasileiro deve se expressar em dois eixos fundamentais, já delineados linhas acima, um cultural e um político-jurídico. Para o primeiro os bens culturais singulares não podem ser mercadorias; e para o segundo, Maia adota a possibilidade de adaptar o Patriotismo às atividades desenvolvidas na Europa.

No caso brasileiro, se não tomar cuidado, você pode ficar depressivo, diante dos níveis assustadores de exclusão ${ }^{52}$ e considerando que o nosso processo histórico-cultural é recente. A globalização, bem como as discussões do multiculturalismo, contribui para o enfraquecimento dos vínculos de identidade, o que não impede a busca pelos demais grupos que respeitam as diversidades culturais.

Cabe-nos perguntar se o modelo de luta por reconhecimento em sociedades pósconvencionais é razoável e aceitável. Este modelo pode ser reconhecido nos casos das lutas feministas ou raciais, por exemplo, acusando a democracia e o seu modelo.

Para ele, não haveria reconhecimento das identidades modernas dos indígenas na política deliberativa, pois a conservação desta forma de vida dependeria de três alternativas, que são inaceitáveis: (i) negar a vida quando se desintegra da comunidade; (ii) negação da forma de vida pela participação política e adoção de um modelo alheio de política; ou (iii) muitos teriam que participar dela, fomentando o primado da decisão de cada um.

Mesmo no caso de defender o direito dos indígenas, eles teriam que utilizar-se de um modelo normativo do estado democrático de direito para fazer esta escolha. Por estes motivos que Durão concluiu que o modelo habermasiano mostra-se não suficiente para apresentar resposta para grupos ou etnias que, com boas razões, não podem adotar a substância ética do estado democrático de direito ${ }^{53}$. Algo nesse sentido que será também falado no tópico seguinte.

Salientamos mais uma vez que o modelo foi cunhado na Europa, particularmente na Alemanha, o que marca bem a sua existência e não deve ser desconsiderado. O Brasil não restou desfigurado no pós II Guerra Mundial, havendo necessidade de se criar um contexto histórico, no qual Patriotismo deve ser visto com ressalvas aqui nas terras latinas do sul.

\footnotetext{
${ }^{50}$ Muito provavelmente porque estes países possuem outros contextos históricos, sendo mesmos, durante um considerável período, colônias de países europeus, que foram os responsáveis pela criação destes conceitos para as suas próprias realidades históricas, geográficas, institucionais. A mera tentativa de reproduzi-los ou copiá-los sem realização de um filtro perante as nossas especificidades, levar-nos-á, novamente, a crise dos colonizados, isto é, a aparente "certeza" de que sempre serão inferiores aos seus colonos, que exerceram e exercem uma dominação epistemológica forte, incisiva e ainda assim muitas vezes imperceptível.

51 MAIA, Antônio C. "Diversidade cultural, identidade nacional brasileira e patriotismo constitucional". In: Diversidade Cultural Brasileira: Edições Casa de Rui Barbosa. 2005, Rio de Janeiro, p. 7.

52 MAIA, Antônio C. "Diversidade cultural, identidade nacional brasileira e patriotismo constitucional". In: Diversidade Cultural Brasileira: Edições Casa de Rui Barbosa. 2005, Rio de Janeiro, p. 1.

53 DURÃO, 2002, p. 74-6, apud MONICA, Eder Fernandes. "A Ideia de Patriotismo Constitucional e Sua Aplicação no Brasil”. Confluências: Revista Interdisciplinar de Sociologia e Direito, p. 5-22, 2007, p. 16.
} 
Antônio Maia fez uma interpretação deste modelo de Habermas de forma mais republicanistas, tentando adaptá-lo a nossa realidade. Ainda assim o Estado Democrático de Direito não consegue resolver todos os problemas da sociedade contemporânea e por este motivo, nem os modelos que se servem dele para apontar os problemas existentes nos contextos.

\subsection{Balanços Parciais}

Diante de todo o exposto no artigo, tentou-se encontrar teorias para lidar com a diversidade e a inclusão, plausível em termos democráticos, valendo-se principalmente da teoria do Patriotismo Constitucional de Habermas, que advoga a aplicação imparcial do direito democrático à pluralidade, garantindo que o próprio direito realize normativamente as diferenças, objetivando a lealdade dos cidadãos diante da Carta Constitucional, especialmente, quanto aos direitos humanos e os princípios fundamentais.

Apresentou-se a noção do conceito chave elaborado por Habermas, depois por Arroyo, numa perspectiva mais republicanistas e por fim, a aplicação no Brasil do Patriotismo feito por Maia e algumas breves considerações nossas, diante dos recentes fenômenos nacionais de ordem política e social.

Acredita-se que essa preocupação é fundamental no contexto da América da Latina, colonizada por diferentes países, e que busca delinear o seu papel na história e o que ela é (ou representa), resultando disso a importância do estudo do tema, mesmo que atualmente haja outros tópicos de maior interesse geral dos acadêmicos.

Não obstante a nossa diversidade e as críticas elaboradas, advoga-se pelos pontos positivos de se criar vínculos identitários fortes e coerentes, mesmo que sobre as bases da Carta Constitucional (Direitos Humanos e Princípios Fundamentais), fazendo frente a homogeneização cultural da globalização, mas também em razão do Capitalismo Oligopolista atual.

Como salientado, razoável é entender que muitos outros problemas que afligem a vida pública de uma coletividade não são resolvidos tão somente com uma forte lealdade à Constituição, mutável e contingente por excelência.

Os anos se passaram, mas os desafios quanto à pluralidade e o respeito permanecem. Portanto, interessante que todo aquele que pesquisa a temática, jurista ou não, debruce-se sobre o tema, a fim de alcançarmos compreensões mais abrangentes destes fenômenos, para então propostas de resolução mais efetivas e completas.

\section{4 É REALMENTE POSSÍVEL APLICAR ESTE CONCEITO NO BRASIL?}

Neste ponto do artigo, após analisadas brevemente as posições de Habermas, de Arroyo e de Maia, nos é lícito apontarmos algumas questões fáticas que não parecem bem resolvidas para a aplicação desta teoria no Brasil, sendo imprescindível considerar estas peculiaridades nacionais, sob pena de falhar consideravelmente. Feita esta nota introdutória prossigamos para o objetivo deste escrito. 
Como ter patriotismo constitucional com (i) uma constituição anacrônica em muitos casos, ora defendendo A e ora anti-A e (ii) com os atuais processos judiciais penais, como a Lava Jato e suas derivações, nas quais não se respeita os procedimentos e garantias constitucionalmente estabelecidas, como o devido processo, a imparcialidade do julgador, as normas quanto às provas, sendo que, para agravar a situação, recebem estas operações e os seus consectários o apoio de número significativo da população? Há espaço efetivo para um patriotismo constitucional no Brasil?

Nas Manifestações de 2013 (ou Jornadas de 2013), na qual houve uma tentativa de radicalizar a democracia, com as pessoas nas ruas, apresentando as suas demandas, exercendo a titularidade do Poder Constituinte ${ }^{54}$, legítimo e democrático e por parte do Estado vem uma resposta de repressão e autoritarismo?

\subsection{A Democracia como um decisivo valor constitucional}

Continuando o tema da Democracia, é claro que ela própria é considerada um valor constitucional a ser seguido, tendo ainda forte relação com a Soberania, como não poderia deixar de ser, mas limitemo-nos ao seu aspecto de valor constitucional e nesse sentido, que possui uma carga altamente considerável para todos os cidadãos patriotas, que desejam dar cumprimento a esse novo modelo de Patriotismo Constitucional.

O novo modelo permitiria gerar "uma cultura cívica em favor da Democracia". No Brasil, se a população vai às ruas em busca de Democracia, ou melhor, tentando praticá-la, é impiedosamente massacrada e submetida a agressão do Estado, por meio dos agentes, que sempre atuam sob a chancela e o comando dos nossos representantes, nesse caso do Poder Executivo, que, em tese, seriam os representantes do povo.

Mas se o povo quer ir para ruas, exercendo diretamente a democracia e, portanto, afastando desde já os poderes dos representantes (um argumento lógico-dedutivo), como esses representantes da população manifestam-se de forma contrária, isto é, coibindo, direta ou indiretamente, esse desejo, essa vontade da população, em que sentido esse Patriotismo Constitucional fortaleceria a cultura democrática no país?

A necessidade de aculturação política parece que primeiro passaria pelos representantes da população, que por vezes têm amnésia quanto à natureza das suas funções, bem como a quem eles devem satisfação.

\section{CONCLUSÃO: DE QUEM DEPENDE O PATRIOTISMO CONSTITUCIONAL?}

O patriotismo constitucional se dependesse somente da população talvez fosse mais fácil se expressar, pois parece existir realmente um movimento deveras plural (a partir dos

\footnotetext{
${ }^{54}$ Para saber mais a respeito deste conceito de Poder Constituinte, ver NEGRI, Antônio. O Poder Constituinte: Ensaio Sobre as Alternativas da Modernidade. 2a edição. Rio de Janeiro: Editora Lamparina, 2015. Tradução de Adriano Pilatti.
} 
vários coletivos que são fundados no país, sob as mais diferentes bandeiras) cujo objetivo geral seria a concretização dos direitos constitucionais exarados na Carta Magna do País.

Mas quando há a necessidade (se é que esta necessidade existe) de vinculação institucional, isto é, dos aparelhos burocráticos do Estado, pode ser que venha a ser dificultado esse processo de patriotismo, considerando as imensas falhas das instituições nacionais.

Como ser patriota se os próprios agentes estatais não o são? Vide a Lava Jato novamente. Vide as ações policiais diante das populações socioeconomicamente vulneráveis, que habitam em comunidades e que normalmente também são negras ${ }^{55}$.

A necessidade, para nós, é real e deve ser apreciada, considerando que (i) os próprios agentes estatais são primeiramente cidadãos e como segundo aspecto (ii) a própria noção de Estado e do seu papel tanto para a vida pública quanto para a vida privada do país, pois a forma de atuação estatal repercute diretamente na formação de um sentimento patriótico em todos aqueles que compõem o elemento povo, justamente por ser ele um instrumento agregador, unificador e mesmo facilitador em vários sentidos, como o é neste de criar este sentimento, que se empodera indubitavelmente quando o próprio Estado, por meio dos seus agentes, cumpre e respeita os valores constitucionais.

Entendemos que a vinculação aos Direitos Humanos estabelecidos na Carta Constitucional deve ser tarefa de todos, agentes estatais ou não, abarcando os cidadãos. No Brasil, pelo menos, acredito estarmos muito distantes dessa vinculação a princípios de direitos fundamentais, em que pese haver uma série de pessoas, instituições e grupos que lutam diariamente por uma sociedade mais justa, utilizando o Direito como um instrumento na efetivação das garantias constitucionalmente previstas para todos os cidadãos ${ }^{56}$.

Há ainda um longo caminhar a trilhar, com fortes obstáculos a vencer, considerando factualmente a nossa realidade sócio-política-cultural, mas em tese e se considerarmos o Patriotismo Constitucional como meta a ser alcançada, talvez seja um conceito que possa vir a ser útil para a realidade brasileira.

Do contrário, poderemos estar apenas executando uma importação teórica acriticamente, como reiteradamente fazemos (vide a nossa história constitucional e políticojurídica), talvez por falsamente acreditarmos que as produções teóricas da Europa são necessariamente melhores do que as nossas, nacionais ou da América do Sul em geral (países colonizados), pelo simples fato de terem saído das antigas Metrópoles e que talvez ainda sejam metrópoles epistêmicas, culturais, teóricas e filosóficas para todos nós, de terrae brasilis.

\footnotetext{
55 Dentre muitos textos, artigos e livros, consultar BARÓN, Francho. As favelas se levantam contra a violência policial. Jornal El País, 19 de abril de 2014. Disponível em: <https://brasil.elpais.com/brasil/2014/04/20/politica/1397952771_527057.html>. Acesso em 13 de agosto de 2017.

ZACCONE, Orlando. "Para combater a violência na cidade, produzimos violência nas favelas": depoimento. [15 de setembro de 2017]. Rio de Janeiro: Revista Carta Capital. Entrevista concecida a Débora Melo. Disponível em: < https://www.cartacapital.com.br/sociedade/para-combater-a-violencia-na-cidade-produzimos-violencia-nasfavelas>. Acesso em 13 de outubro de 2017.

${ }^{56}$ Dentre os vários existentes, cito, à título de exemplo, os Coletivos atuantes e militantes em favor dos direitos das minorias, como o NAJUP Luiza Mahin (Núcleo de Assessoria Jurídica Universitária Popular), o Coletivo Negro Patrice Lumumba e o CADHu - Coletivo de Advogados de Direitos Humanos.
} 


\section{REFERÊNCIAS}

ARROYO, J. C. V. "Republicanismo, constitucionalismo y diversidad cultural. Más allá de la tolerancia liberal". In: Revista de Estudios Políticos, no 125, 2004. Disponível em:

<http://digital.csic.es/bitstream/10261/9809/1/republicanismo\%20\%2c\%20cosntitucionalsi mo.pdf >. Acessado em 08 de Julho de 2017.

BARÓN, F. As favelas se levantam contra a violência policial. Jornal El País, 19 de abril de 2014. Disponível em:

<https://brasil.elpais.com/brasil/2014/04/20/politica/1397952771_527057.html>. Acesso em 13 de agosto de 2017.

BUNCHAFT, M. E. A Integração do Conceito de Patriotismo Constitucional na Cultura Política Brasileira, 2005. Publicado em Revista Direito, Estado e Sociedade da PUC-Rio. Disponível em: <http://www.jur.puc-

rio.br/revistades/index.php/revistades/article/download/281/254>. Acessado em 07 de Julho de 2017.

COSTA, S. Dois Atlânticos: teoria social, anti-rascismo e cosmopolitismo. Belo Horizonte: UFMG, 2006.

FAVARIM, F. N. Limites da Tolerância Nos Conflitos Entre Grupos Religiosos. 2007. 113 f. Dissertação (Mestrado em Direito) - Programa de Pós Graduação em Direito, Universidade Metodista de Piracicaba, São Paulo. 2007.

GARgARELLA, R. As Teorias da Justiça Depois de Rawls - Um Breve Manual de Filosofia Política. 1a edição. São Paulo: Editora Martins Fontes, 2008.

HABERMAS, J. Identidad Nacional y Identidad Postnacional-entrevista com Jean Marc Ferry. In: HABERMAS, Jürgen. Identidades Nacionales y Postnacionales. Madrid: Tecnos, 1998.

Disponível em:

<https://drive.google.com/file/d/0B5DgQx9G3Yu2cGx5SmRFV3pqZms/view>. Acessado em 08 de Julho de 2017.

Disponível em:

. A Inclusão do Outro. Tradução George Sperber. São Paulo: Loyola, 2002.

<https://auriusfilosofia.files.wordpress.com/2013/11/habermas_a_incluso_do_outro__.pdf>. Acessado em 08 de Julho de 2017.

. O Estado-nação europeu frente aos desafios da globalização. In: Novos Estudos CEBRAP, n. 43, novembro de 1995. Disponível em:

<http://novosestudos.uol.com.br/produto/edicao-43/>. Acessado em 07 de Julho de 2017.

HONNETH, A. Luta por Reconhecimento: A Gramática Moral dos Conflitos Sociais. Tradução de Luiz Repa; apresentação de Marcos Nobre. São Paulo: Editora 34, 2003.

LEISTER, M.; TREVISAN, E. A Tolerância às Diversidades: Base da Efetivação da Sociedade Democrática. In: Ana Maria Viola de Sousa; Noe Lopes Zuñiga; Grasielle Augusta Ferreira Nascimento. (Org.). Direitos Humanos e Minorias. 1edição. Lorena: UNISAL, 2015, v. 4, p. 112.

MAIA, A. C. "Diversidade cultural, identidade nacional brasileira e patriotismo constitucional". In: Diversidade Cultural Brasileira: Edições Casa de Rui Barbosa. 2005, Rio de 
Janeiro, p. 115-156. Disponível em:

<http://www.casaruibarbosa.gov.br/seminario/DiversidadeCultural/Antonio_Cavalcanti.pdf >. Acessado em 07 de Julho de 2017.

MELO, D. Ernst Nolte e a Hitoriografia Revisionista. Disponível em:

$<$ http://blogjunho.com.br/ernst-nolte-e-a-historiografia-revisionista/>. Acessado em 07 de julho de 2017.

MIGUEL, L. F. Consenso e conflito na teoria democrática: para além do "agonismo". Lua Nova (Impresso), v. 92, p. 13-43, 2014.

MONICA, E. F. "A Ideia de Patriotismo Constitucional e Sua Aplicação no Brasil".

Confluências: Revista Interdisciplinar de Sociologia e Direito, p. 5-22, 2007. Disponível em:< http://www.confluencias.uff.br/index.php/confluencias/article/view/102>. Acessado em 07 de Julho de 2017.

NEGRI, A. O Poder Constituinte: Ensaio Sobre as Alternativas da Modernidade. 2a edição. Rio de Janeiro: Editora Lamparina, 2015. Tradução de Adriano Pilatti.

SILVA, G. J.; SOUZA, J. L. Educar Para a Diversidade Étnico-Racial e Cultural: Desafios da Educação Inclusiva no Brasil. Disponível em:

<https://www.revistas.ufg.br/interacao/article/view/4256/4180>. Acessado em 08 de Julho de 2017.

SILVA, R.. Visões da liberdade: republicanismo e liberalismo no debate teórico

contemporâneo. Lua Nova: Revista de Cultura e Política, p. 181-215, 2015.

TOCQUEVILLE, A de. A Democracia na América. Trad. Neil Ribeiro da Silva. 1a ed. São Paulo: Folha de São Paulo, 2010. [Coleção Folha: livros que mudaram o mundo; v.16].

WALZER, M. Da tolerância. São Paulo: Martins Fontes, 1999.

ZACCONE, O. "Para combater a violência na cidade, produzimos violência nas favelas": depoimento. [15 de setembro de 2017]. Rio de Janeiro: Revista Carta Capital. Entrevista concecida a Débora Melo. Disponível em: <

https://www.cartacapital.com.br/sociedade/para-combater-a-violencia-na-cidadeproduzimos-violencia-nas-favelas>. Acesso em 13 de outubro de 2017. 